\title{
The Hutchison Young Scientist Award
}

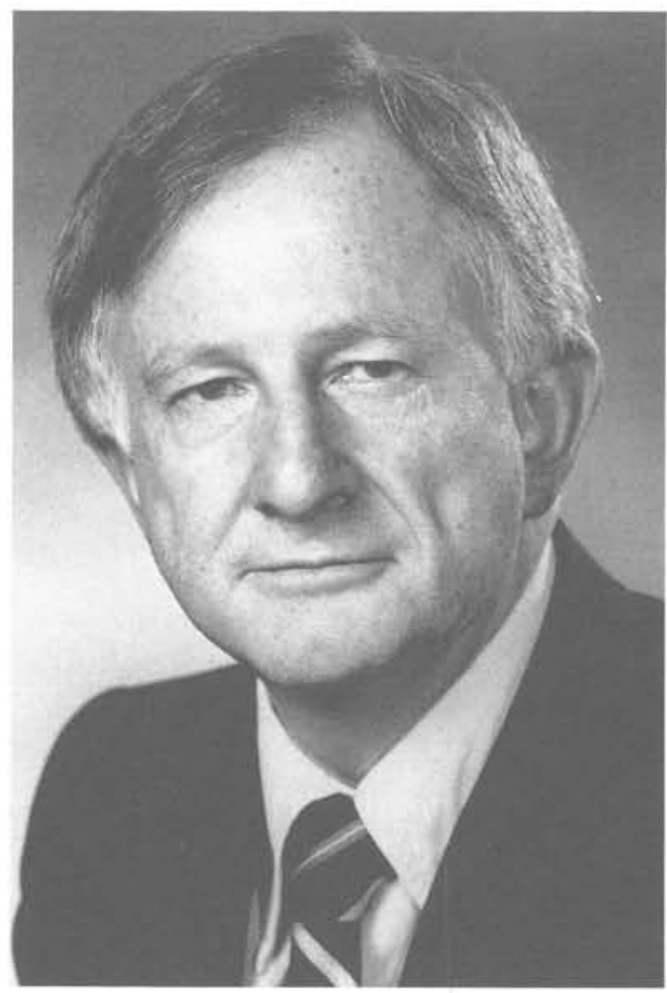

Dr. William Watt Hutchison was President of the International Union of Geological Sciences (IUGS) at the time of his death in 1987. For many years, he derived professional inspiration from collaborative work with geoscientists around the world. He applied many of the ideas developed during discussions with young, creative scientists to projects, activities and policies in Canada, where he served in the federal government as Assistant Deputy Minister for Earth Sciences. He saw in organizations such as the IUGS, a means of improving communication and understanding in areas vitally important to global economic, environmental and social well-being. Wishing to encourage progress in international geoscientific collaboration, he endowed a portion of his Estate toward the maintenance of a fund to enable deserving young geoscientists from around the world to benefit from participation in IUGS-sponsored activities. The awards are tenable in any country that is a member of the IUGS. Each award consists of a cash payment generally not exceeding $\$ 1,500.00$ (US), plus travel costs (where applicable) to and from the meeting or scientific field excursion; awards are tenable for the duration of the meeting.

The awards are granted to scientists under the age of 35 who are pursuing studies, research or work in the disciplines fostered by IUGS, and who bring specialized knowledge to the meeting. Candidates should demonstrate how they and their sponsored agency or university will benefit from such participation. Applications must be completed in duplicate in English and submitted to both the President of IUGS and the Executrix of the Hutchison Estate, who together with one other member of the IUGS Bureau act as the Selection Committee.

The first three recipients of the Hutchison Young Scientist Award, announced recently, will be attending the Washington Congress. They are Witold Zuchiewicz, an assoicate professor with the Jagiellonian University in Krakow, Poland, who will be presenting papers at the 28th IGC on the early Quaternary stratigraphy of fluvial deposits in the Polish Carpathians and comparing the morphotectonics of the Carpathians and the southern Alps; Nwoye Barth Ekwueme, a lecturer at the University of Calabar in Nigeria, who will present his findings on the tectonothermal evolution of the Oban Massif (Nigeria); and Maria Beatriz Aguirre-Urreta, a researcher with the National Council for Scientific Research (CONICET) in Buenos Aires, Argentina, who works on Cretaceous rocks and especially on ammonites. Further information may be obtained from the President of IUGS, Prof. Umberto Cordani (Instituto de Geociencias, Universidade de São Paulo, CEP 01498 , C.P. 20.899, São Paulo, Brazil) and the Executrix of the Hutchison Estate, Dr. Vera Lafferty (Canada Oil and Gas Lands Administration, 355 River Road, Ottawa, Ontario, Canada K1A 0E4). 


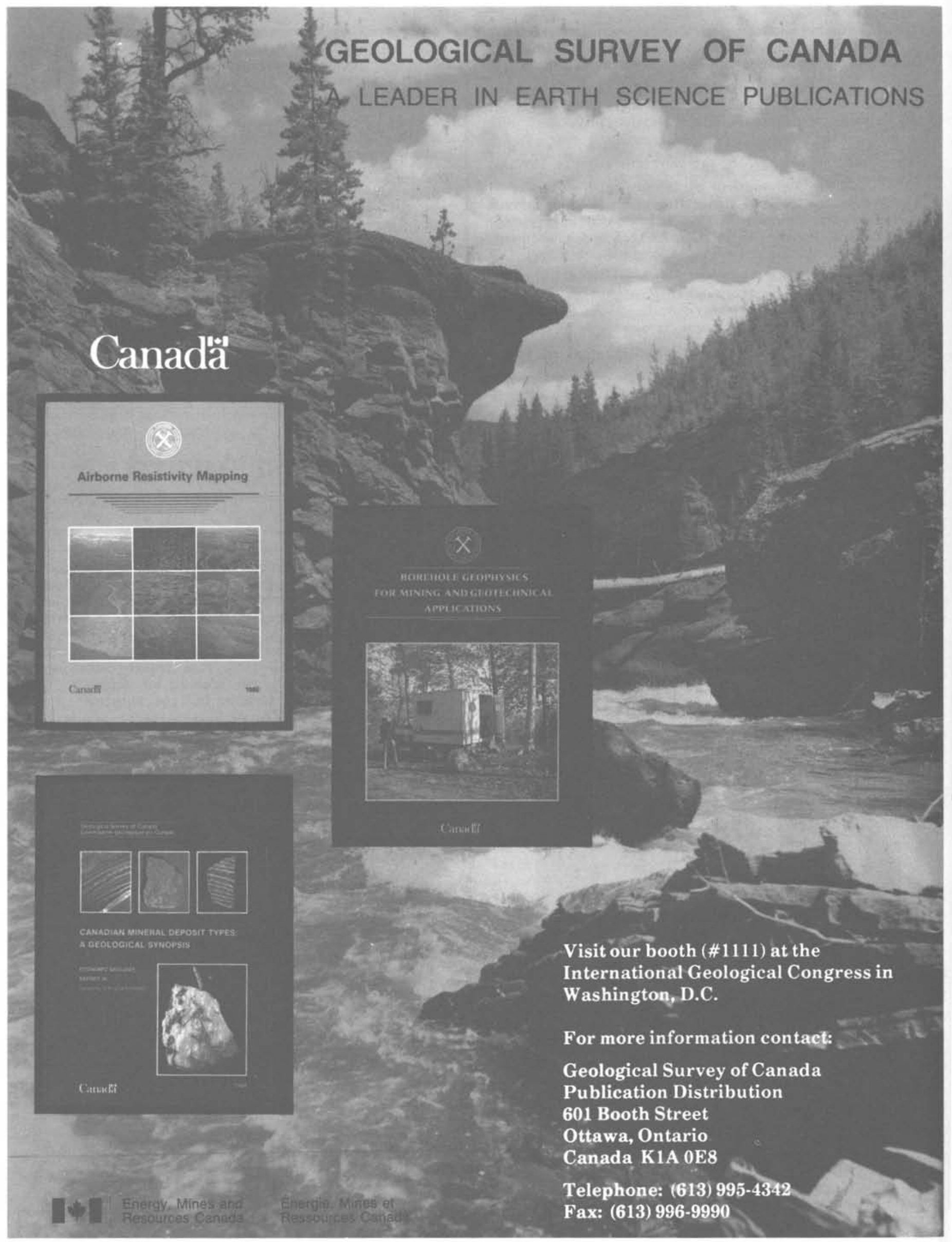

